\title{
МНОГОЛЕТНЯЯ ДИНАМИКА ЗАГРЯЗНЕНИЯ РЕКИ ПО ДАННЫМ АНАЛИТИЧЕСКОГО ЦЕНТРА КОНТРОЛЯ КАЧЕСТВА ВОД
}

\author{
Мазуркин П.М., Евдокимова О.Ю.
}

ФГБОУ ВПО «Поволжский государственный технологический университет», Йоикар-Ола, Россия (424000, г. Йошкар-Ола, пл. Ленина, 3), е-таil: engineer_87_87@mail.ru

Изучена многолетняя динамика загрязнения реки по результатам лабораторных исследований МУП «Водоканал» г. Йошкар-Ола. Выявлена общая закономерность изменения содержания гидрохимических показателей, в том числе органолептических и химических показателей качества речной воды. Представлены детерминированная закономерность и модель с волновыми функциями в виде асимметричного вейвлет-сигнала. Адекватность полученных закономерностей оценивается по коэффициенту корреляции. Ранжированием значений коэффициентов корреляции выявлены закономерности, которые с наименьшей погрешностью характеризуют изменение содержания загрязняющих веществ в речной воде. Повышение требований к адекватности приводят к снижению количества составляющих, в том числе и волновых членов, биотехнических закономерностей. Отношение значений коэффициента корреляции уравнений динамики с волнами к тренду показывает преимущество сложной по конструкции модели с волновыми составляющими колебательного возмущения на примере щелочности речной воды. Представлен пример сравнения концентраций загрязняющего вещества в виде магния с его предельно-допустимой концентрацией.

Ключевые слова: речная вода, загрязнение, пробы, показатели, волновые функции, коэффициент корреляции.

\section{LONG-TERM DYNAMICS OF THE RIVER POLLUTION ACCORDING TO THE ANALYTICAL CENTRE OF WATER QUALITY CONTROL}

\author{
Mazurkin P.M., Evdokimova O.Y. \\ Volga State Technological University, Yoshkar-Ola, Russia (424000, Yoshkar-Ola, Lenin 3sq.), e-mail: \\ engineer_87_87@mail.ru
}

The long-term dynamics of the river pollution based on laboratory analysis data of MUP "Water canal" Yoshkar-Ola are examined. General biotechnical pattern of changes in the content of hydrochemical indicators including organoleptic and chemical indicators of river water quality are revealed. A deterministic pattern and model with the wave functions in skewness wavelet-signal form are presented. The adequacy of the obtained patterns by the correlation coefficient are measured. The patterns characterizing contaminants changes in the river water with least error are revealed by ranking values of correlation coefficients. Increased requirements for adequacy give rise to quantity reduction of components including wave terms of biotechnical patterns. The ratio of the correlation coefficient of wave dynamic equations to trend shows the advantage of the complex model structures with the wave component of vibrational perturbation as an example alkalinity of river water. An example of a comparison of the contaminant concentration in terms of magnesium and maximum permissible concentration are presented.

Key words: river water, pollution, samples, wave functions, correlation coefficient.

Введение. Существуют множество химических, биологических, физико-химических и физических показателей, определяющих качество речной воды $[1 ; 5 ; 6]$ по видам загрязнения. Нами приняты для моделирования многолетние ежемесячные данные Аналитического центра контроля качества воды МУП «Водоканал» г. Йошкар-Ола в общем случае с 10.06.2002 по 08.12.2011 г. на пробах из водозабора реки Малая Кокшага (табл. 1).

\section{Таблица 1 - Результаты лабораторных испытаний (фрагмент)}




\begin{tabular}{|c|c|c|c|c|c|c|c|c|c|c|c|c|c|}
\hline $\begin{array}{c}\text { № } \\
\Pi / \Pi\end{array}$ & Дата & $\begin{array}{l}\text { Время } \\
\mathrm{T}, \text { сут }\end{array}$ & 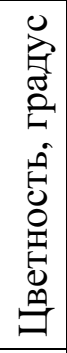 & 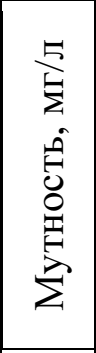 & $\stackrel{I}{a}$ & 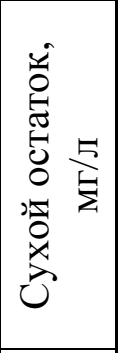 & 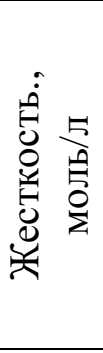 & $\vdots$ & 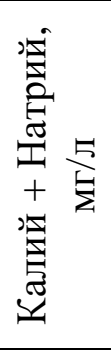 & 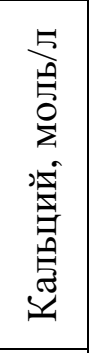 & 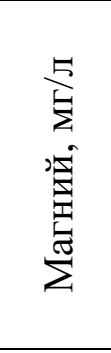 & 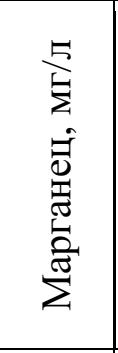 & 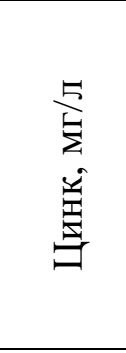 \\
\hline & & & 1 & 2 & 3 & 4 & 5 & $\ldots$ & 21 & 22 & 23 & 24 & 25 \\
\hline 1 & 10.06 .2002 & 0 & 22 & 3.1 & 7.9 & 241.0 & 3.68 & .. & - & 2.57 & - & 0.01 & 0.0037 \\
\hline 2 & 04.07 .2002 & 24 & 11 & 7.7 & 7.6 & 233.0 & 3.66 & ... & - & 2.38 & - & 0.008 & 0.008 \\
\hline 3 & 07.08 .2002 & 58 & 20 & 4.5 & 7.7 & 216.8 & 3.54 & $\ldots$ & - & 2.3 & - & 0.03 & 0.003 \\
\hline 4 & 09.09 .2002 & 91 & 18 & 2.8 & 7.9 & 218.2 & 3.86 & $\ldots$ & - & 2.38 & - & 0.006 & 0.001 \\
\hline 5 & 30.10 .2002 & 142 & 25 & 4.98 & 7.8 & 236.0 & 3.8 & $\ldots$ & - & 2.49 & - & 0.01 & 0.002 \\
\hline$\cdots$ & $\cdots$ & $\cdots$ & $\cdots$ & $\cdots$ & $\cdots$ & $\cdots$ & $\ldots$ & $\cdots$ & $\cdots$ & $\cdots$ & $\cdots$ & $\cdots$ & $\cdots$ \\
\hline 21 & 10.08 .2011 & 3348 & 41 & 2.9 & 8.1 & 228 & 4.1 & .. & 10.5 & 2.6 & 18.3 & 0.031 & 0.0018 \\
\hline 22 & 07.09 .2011 & 3376 & 24 & 2.6 & 8 & 226 & 4.1 & $\ldots$ & 11.8 & 2.5 & 19.52 & 0.044 & 0.0013 \\
\hline 23 & 12.10 .2011 & 3411 & 27 & 1.5 & 8 & 245 & 4.5 & ... & 0.5 & 2.5 & 24.4 & 0.032 & 0.0017 \\
\hline 24 & 14.11 .2011 & 3444 & 21 & 1.90 & 7.9 & 253.0 & 4.6 & $\ldots$ & 21.00 & 2.9 & 18.30 & 0.082 & 0.0012 \\
\hline 25 & 08.12 .2011 & 3468 & 19 & 1.54 & 7.4 & 285.0 & 5.0 & $\ldots$ & 6.50 & 3.3 & 20.74 & 0.094 & 0.0028 \\
\hline
\end{tabular}

В таблице 1 представлены результаты по 25 показателям, включающие органолептические и показатели химического состава воды, по которым проводились регулярные испытания. Шкала времени принята по суткам с началом от даты первого измерения. Тогда относительно этой шкалы абсцисс можно идентифицировать закономерности динамики загрязнения по каждому его виду. Аналитический центр проводил испытания речной воды по 46 показателям, из них достаточно заполненными по измеренным значениям были 25 параметров, а измерения по $K+N a$ и $M g$ стали проводить с января 2009 года.

Модель динамики загрязнения. Математическим моделированием [3; 4] получена общая модель изменения гидрохимического показателя во времени (1)

$$
C=C_{1}+C_{2}+\sum_{k=1}^{m} C_{3 k}
$$

$C_{1}=a_{1} \exp \left(-a_{2} T^{a_{3}}\right)$

$C_{2}=a_{4} T^{a_{5}} \exp \left(-a_{6} T^{a_{7}}\right)$

$C_{3 k}=\sum_{k=1}^{m} a_{8 k} T^{a_{9 k}} \exp \left(-a_{10 k} T^{a_{11 k}}\right) \cos \left(\pi T /\left(a_{12 k}+a_{13 k} T^{a_{14 k}}\right)+a_{15 k}\right)$, 
где $C$ - гидрохимический показатель; $C_{1}$ - первая составляющая, показывающая по закону экспоненциального роста или гибели естественную часть динамического процесса; $C_{2}-$ вторая составляющая динамики загрязнения речной воды по каждому виду загрязнителя, которая показывает стрессовое возбуждение загрязнителя со временем (в некоторых видах загрязнения этой составляющей может и не быть); $C_{3 k}-$ волновая составляющая изменения содержания гидрохимического показателя; $k$ - номер волновой составляющей формулы (1); $m$ - количество волновых составляющих в статистической модели, шт.; $a_{1} \ldots a_{15}$ - параметры статистической модели (1), определяемые в программной среде CurveExpert по статистической выборке из данных таблицы 1.

Эта программная среда имеет максимальное число неизвестных параметров модели 19 , поэтому для повышения уровня адекватности уравнений требуется специальная программа.

Пример. Для примера покажем изменение концентрации в речной воде химическим веществом $K+N a$ за период 26.01.2009 - 08.12.2011 г. По обобщенной модели (1) нами были выявлены детерминированная закономерность, а также три модели с волновыми функциями в виде асимметричных вейвлет-сигналов.

Детерминированная факторная зависимость без учета второй составляющей (1) с небольшим коэффициентом корреляции $R=0.3495$ слабой тесноты связи имеет вид:

$$
C_{K+N a}=1.84085 \cdot 10^{-30} \exp \left(49.48661 T^{0.04414}\right) .
$$

Дополнительно статистическим моделированием получили формулу с одной волной:

$$
C_{K+N a}=C_{1}+C_{3},
$$

$C_{1}=1.03014 \cdot 10^{-24} \exp \left(56.24940 T^{0.0026544}\right), C_{3}=A \cos (\pi T / p+0.55589)$,

$A=7.54476 \cdot 10^{-65} T^{21.81110} \exp (-0.0083675 T), p=6773.3228-1.74329 T$,

где $C_{1}$ - первая составляющая роста концентрации $K+N a ; C_{2}$ - вторая составляющая равна нулю; $C_{3}$ - третья составляющая колебательного возмущения; $A$ - половина амплитуды колебательного возмущения; $p$ - половина периода волнового изменения содержания $K+N a$ в речной воде.

Следующая модель получена исходя из вычислительных возможностей программной среды. При наращивании формулы (2) получили уравнение из четырех составляющих:

$$
C_{K+N a}=C_{1}+C_{3}+C_{4}+C_{5},
$$

$C_{1}=1.12815 \cdot 10^{-24} \exp \left(56.33968 T^{0.0024573}\right)$,

$C_{3}=A_{1} \cos \left(\pi T / p_{1}-0.83718\right)$,

$A_{1}=7.10237 \cdot 10^{-65} T^{21.90915} \exp (-0.0085882 T), p_{1}=7472.9258-1.90518 T$, 
$C_{4}=A_{2} \cos \left(\pi T / p_{2}+1.45666\right)$,

$A_{2}=46.5835 \exp (-0.0011171 T), p_{2}=266.95362-0.014744 T^{1.11798}$,

$C_{5}=A_{3} \cos \left(\pi T / p_{3}+2.94036\right)$,

$A_{3}=1.05360 \cdot 10^{-140} T^{45.08514} \exp (-0.012330 T)$,

$p_{3}=41.69115-7.0024332 \cdot 10^{-5} T$,

где $C_{4}$ - четвертая составляющая колебательного возмущения; $A_{2}$ - половина амплитуды колебательного возмущения четвертой составляющей; $p_{2}-$ половина периода волнового изменения четвертой составляющей; $C_{5}$ - пятая составляющая колебательного возмущения; $A_{3}$ - половина амплитуды колебательного возмущения пятой составляющей; $p_{3}-$ половина периода волнового изменения пятой составляющей.

На рисунке 1 представлен график изменения концентрации калия и натрия за 1047 суток.

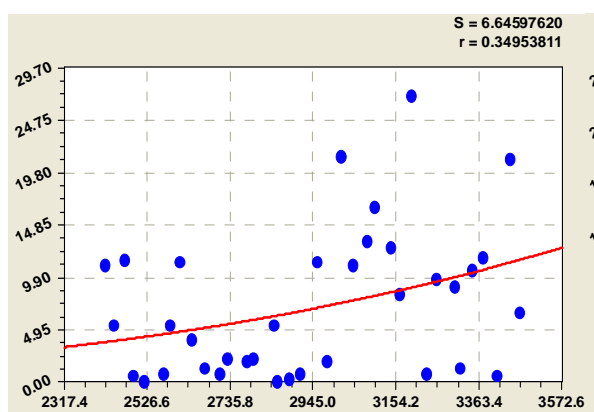

a

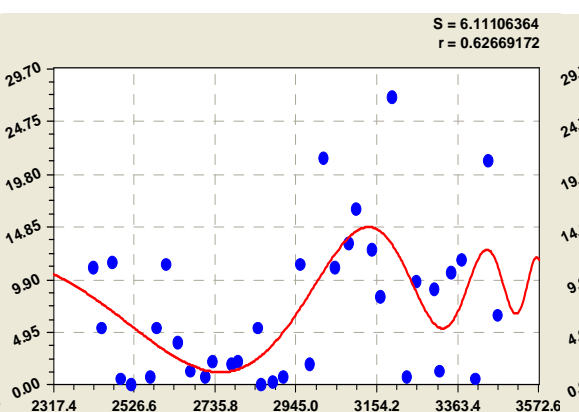

6

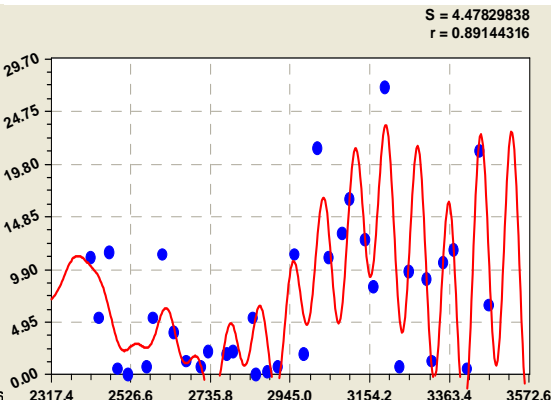

B

Рис. 1. Изменение содержания $K+N a:$ a - детерминированная модель (2); б - модель с одной волновой составляющей (3); в - модель (4) по возможностям программной среды

Изменение содержания калия и натрия в речной воде лучше всего характеризует модель (4), коэффициент корреляции которой составил 0.8914. Из рисунка 1в видно, что на 2736 сутки (декабрь 2009 года) концентрация в речной воде была наименышей, затем содержание $K+N a$ увеличивалось и достигло в начале 2011 года максимальных значений.

Анализ результатов. Коэффициент корреляции (табл. 2) позволяет оценить адекватность полученных закономерностей.

Таблица 2 - Коэффициент корреляции между переменными факторами [3]

\begin{tabular}{|c|c|}
\hline $\begin{array}{c}\text { Интервал } \\
\text { коэффициета корреляции }\end{array}$ & Характер тесноты связи \\
\hline 1.0000 & однозначная \\
\hline $0.9000 \ldots 1.0000$ & сильнейшая \\
\hline $0.7000 \ldots 0.9000$ & сильная \\
\hline $0.5000 \ldots 0.7000$ & средняя \\
\hline
\end{tabular}




\begin{tabular}{|c|c|}
\hline $0.3000 \ldots 0.5000$ & слабоватая \\
\hline $0.1000 \ldots 0.3000$ & слабая \\
\hline $0.0000 \ldots 0.1000$ & слабейшая \\
\hline 0.0000 & нет связи \\
\hline
\end{tabular}

Для этого нами проставлены ранги по убыванию значений коэффициента корреляции. Ранг приняли равным нулю для самой высокоадекватной закономерности по модели (1), фактический коэффициент корреляции которой составил 0.8914 (изменение концентрации $K+N a$ в речной воде).

В таблице 3 показана адекватность $25 \times 3=75$ закономерностей по модели (1).

Таблица 3 - Коэффициенты корреляции модели (1) по разной структуре
идентификации

\begin{tabular}{|c|c|c|c|c|c|c|c|c|c|}
\hline \multirow[b]{2}{*}{ Показатели } & \multicolumn{6}{|c|}{ Коэффициент корреляции модели (1) } & \multicolumn{3}{|c|}{ Кратность } \\
\hline & $\begin{array}{c}\text { тренд } \\
r_{t r}\end{array}$ & $\begin{array}{c}\text { ранг } \\
i\end{array}$ & $\begin{array}{c}\text { с одной } \\
\text { волной } \\
r_{t r+\tilde{1}}\end{array}$ & $\underset{i}{\text { ранг }}$ & $\mid \begin{array}{c}\text { с вол- } \\
\text { нами } \\
r\end{array}$ & $\begin{array}{c}\text { ранг } \\
i\end{array}$ & $\frac{r_{t r+\tilde{1}}}{r_{t r}}$ & $\frac{r}{r_{t r}}$ & $\underset{j}{\text { ранг }}$ \\
\hline Цветность, градус & 0.1639 & 50 & 0.3767 & 41 & 0.5082 & 29 & 2.3 & 3.1 & 5 \\
\hline Мутность, мг/л & 0.2305 & 46 & 0.4887 & 31 & - & - & 2.1 & - & - \\
\hline $\mathrm{pH}$ & 0.4694 & 34 & 0.7719 & 6 & - & - & 1.6 & - & - \\
\hline Сухой остаток, мг/л & 0.0000 & 59 & 0.5482 & 25 & 0.7372 & 9 & $\infty$ & $\infty$ & $\infty$ \\
\hline Жесткость, моль/л & 0.1267 & 52 & 0.5775 & 20 & - & - & 4.6 & - & - \\
\hline Щелочность общая, моль/л & 0.0533 & 58 & 0.5006 & 30 & 0.7725 & 5 & 9.4 & 14.5 & 0 \\
\hline Окисляемость перм., мгО/л & 0.1937 & 48 & 0.5723 & 22 & 0.6543 & 15 & 3.0 & 3.4 & 4 \\
\hline БПК-20, мГО/л & 0.2815 & 44 & 0.4192 & 37 & 0.5532 & 24 & 1.5 & 2.0 & 7 \\
\hline Взвешенные вещества, мг/л & 0.1852 & 49 & - & - & - & - & - & - & - \\
\hline АСПАВ, мг/л & 0.4228 & 36 & 0.6195 & 18 & - & - & 1.5 & - & - \\
\hline Нефтепродукты, мг/л & 0.1263 & 53 & 0.4776 & 33 & - & - & 3.8 & - & - \\
\hline Фенолы, мг/л & 0.6943 & 11 & 0.7803 & 4 & 0.8363 & 1 & 1.1 & 1.2 & 10 \\
\hline Аммоний солевой, мг/л & 0.2391 & 45 & 0.3499 & 42 & - & - & 1.5 & - & - \\
\hline Нитриты, мг/л & 0.3960 & 38 & 0.5425 & 27 & - & - & 1.4 & - & - \\
\hline Нитраты, мг/л & 0.1424 & 51 & 0.6761 & 13 & - & - & 4.7 & - & - \\
\hline Сульфаты, мг/л & 0.4844 & 32 & 0.6162 & 19 & 0.7385 & 8 & 1.3 & 1.5 & 8 \\
\hline Фосфаты, мг/л & 0.4534 & 35 & 0.5480 & 26 & - & - & 1.2 & - & - \\
\hline Фториды, мг/л & 0.5606 & 23 & 0.6906 & 12 & 0.7334 & 10 & 1.2 & 1.3 & 9 \\
\hline Хлориды, мг/л & 0.0749 & 56 & 0.6503 & 16 & 0.7529 & 7 & 8.7 & 10.1 & 1 \\
\hline
\end{tabular}




\begin{tabular}{|l|c|c|c|c|c|c|c|c|c|}
\hline Железо общее, мг/л & 0.0737 & 57 & - & - & - & - & - & - & - \\
\hline Калий + натрий, мг/л & 0.3495 & 43 & 0.6267 & 17 & $\mathbf{0 . 8 9 1 4}$ & 0 & 1.8 & 2.6 & 6 \\
\hline Кальций, моль/л & 0.0886 & 55 & 0.5326 & 28 & 0.6722 & 14 & 6.0 & 7.6 & 2 \\
\hline Магний, мг/л & $\mathbf{0 . 0 0 0 0}$ & 59 & 0.5762 & 21 & 0.7806 & 3 & $\infty$ & $\infty$ & $\infty$ \\
\hline Марганец, мг/л & 0.1123 & 54 & 0.3798 & 40 & 0.7813 & 2 & 3.4 & 7.0 & 3 \\
\hline Цинк, мг/л & 0.2107 & 47 & 0.3900 & 39 & - & - & 1.9 & - & - \\
\hline
\end{tabular}

Из таблицы 3 видно, что слабую связь имеют закономерности с одной составляющей, среднюю - с одной волновой составляющей и сильную - закономерности, принимающие конструкцию модели (1).

В таблице 3 также показана кратность: отношение коэффициентов корреляции закономерности с одной волновой составляющей $r_{t r+1}$ К тренду $r_{t r}$ и отношение коэффициентов корреляции уравнений с волнами $r$ к тренду $r_{t r}$.

Ранговое распределение адекватности моделей. Для оценки погрешности закономерностей нами проведено ранжирование значений коэффициентов корреляции.

Закономерность изменения коэффициента корреляции в зависимости от рангового распределения (рис. 2) имеет вид:

$$
r=0.88941 \exp \left(0.0032904 i^{0.98702}\right)-0.061248 i^{0.45621} \exp \left(0.017081 i^{0.99812}\right),
$$

где $r$ - значение коэффициента корреляции; $i$ - ранг.

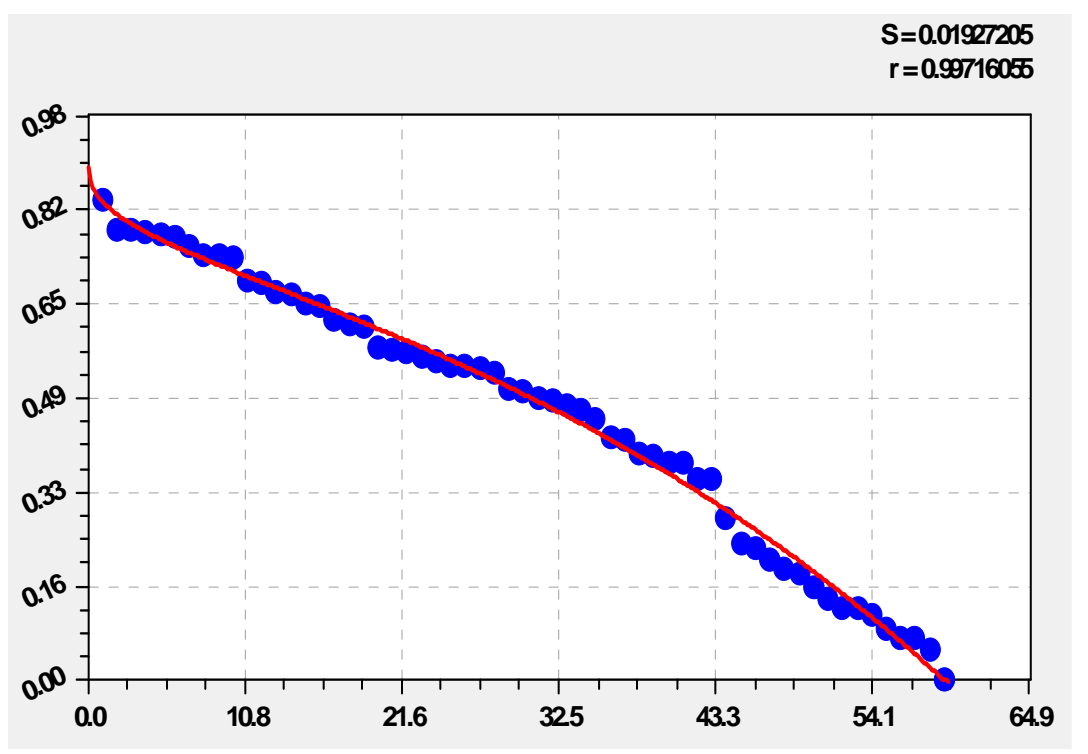

Рис. 2. Ранговое распределение коэффициентов корреляции.

Из рисунка 2 следует, что с повышением требований к адекватности, по росту значений коэффициента корреляции $r$, число уравнений медленно сокращается.

Изменение кратности коэффициентов корреляции (рис. 3) происходит по формуле: 


$$
r / r_{t r}=14.49571 \exp (-0.17861 j)-1.92231 j^{0.30193} \exp \left(-0.0011024 j^{3.03200}\right),
$$

где $r / r_{t r}-$ кратность; $j-$ ранг.

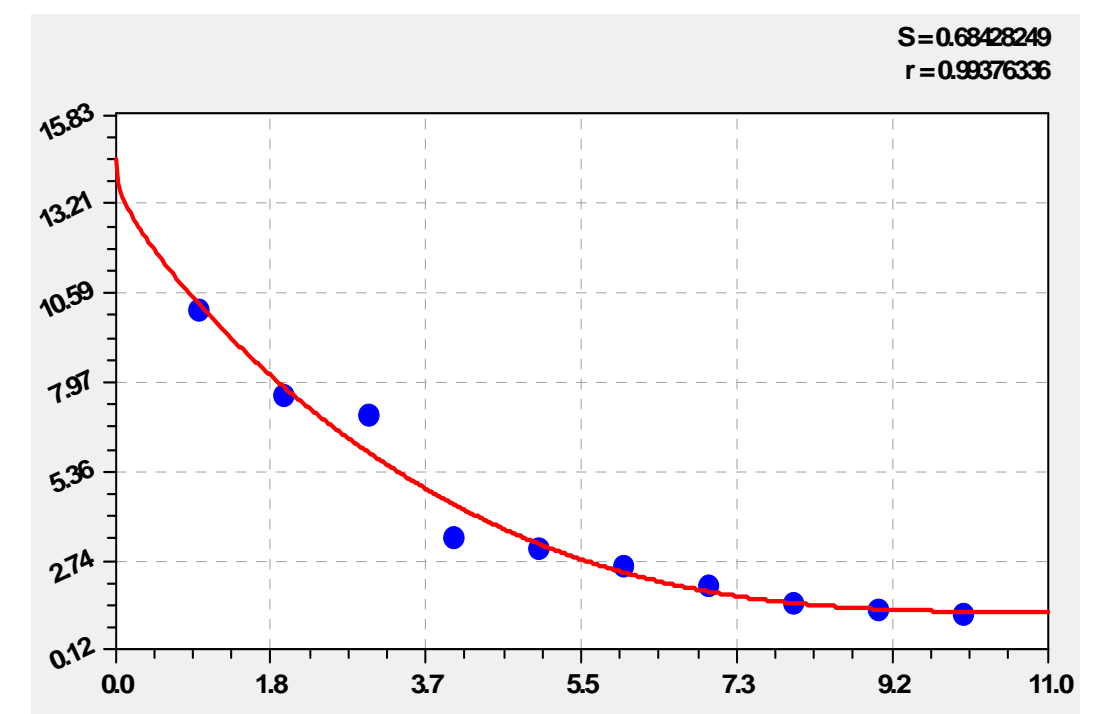

Рис. 3. Ранговое распределение кратности коэффициентов корреляции.

Максимальное значение кратности составляет 14.5, то есть в 14.5 раз закономерность динамики щелочности с волновыми составляющими $(r=0.7725)$ точнее тренда $\left(r_{t r}=0.0533\right)$. Незначительно происходит повышение адекватности с волновыми составляющими по динамике фенола, здесь $r_{t r}=0.6943$, а $r=0.8363$.

В случаях когда тренд принимает среднеарифметическое значение и коэффициент корреляции по тренду $r_{t r}$ равен 0.0000 (сухой остаток и магний), кратность принимает значение $\infty$.

Сравнение концентрации загрязнения с ПДК. Известно, что основным критерием загрязнения воды являются предельно-допустимые концентрации [1;2]. ПДК для магния в воде водных объектов хозяйственно-питьевого и культурно-бытового водопользования составляет 50 мг/л [2].

На рисунке 4а показано среднеарифметическое значение концентрации магния в речной воде, равное $\approx 17$ мг/л, то есть тренд не показывает динамику магния.

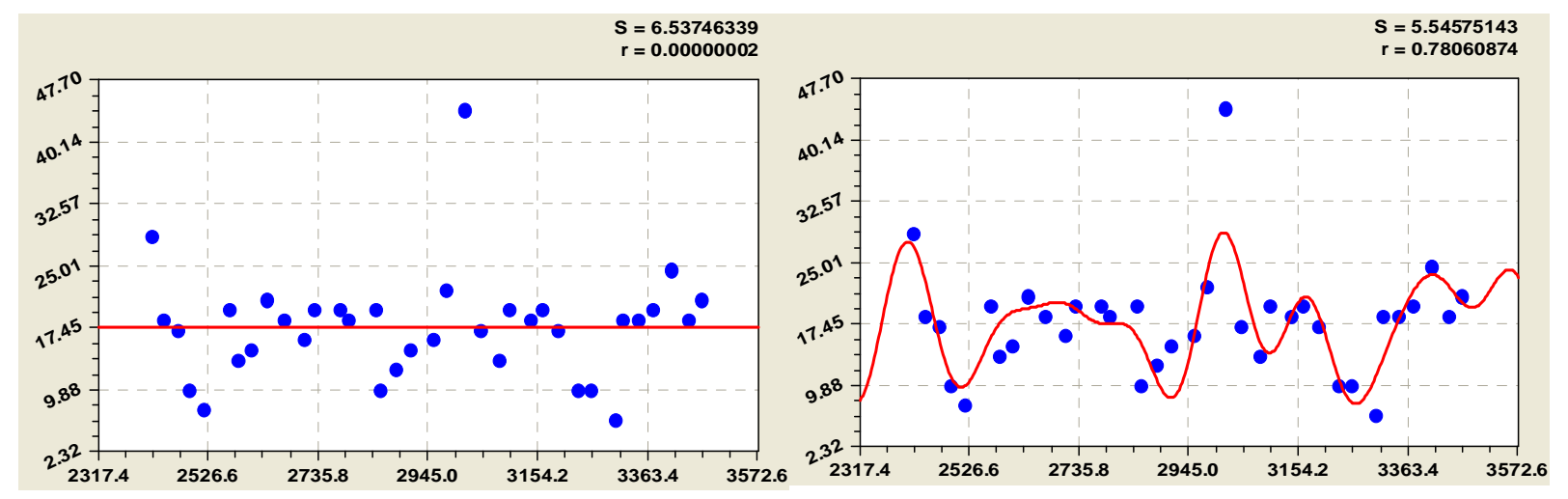


Рис. 4. Сравнение с ПДК: а - тренд; б - общая модель (7).

На рисунке $4 б$ представлена общая модель содержания магния в речной воде (7), где видно, что концентрация магния за период наблюдений не превысила ПДК=50 мг/л.

$$
C_{M g}=C_{1}+C_{3}+C_{4}+C_{5},
$$

$C_{1}=17.28701, C_{2}=0$,

$C_{3}=A_{1} \cos \left(\pi T / p_{1}+0.95440\right)$,

$A_{1}=1.76987 \exp (0.00036291 T), p_{1}=12.82948+0.0075015 T^{1.04780}$,

$C_{4}=A_{2} \cos \left(\pi T / p_{2}-4.96823\right)$,

$A_{2}=1.83683 \cdot 10^{-50} T^{16.69571} \exp (-0.0058340 T), p_{2}=94.90660$,

$C_{5}=A_{3} \cos \left(\pi T / p_{3}+3.58898\right)$,

$A_{3}=5.53965 \cdot 10^{-48} T^{16,20889} \exp \left(-0.0060630 T^{1.01240}\right)$,

$p_{3}=131.78043-0.017796 T^{0.94294}$.

В формуле (7) первая составляющая упростилась по конструкции до постоянного члена.

Из рисунка 46 заметны колебания концентрации магния. Содержание магния в поверхностных водах меняется в течение года: максимальные концентрации наблюдаются в меженный период, минимальные - в период половодья [1].

Заключение. Закономерности с волновыми составляющими колебательного возмущения получают высокие значения критерия тесноты связи. Выявленные закономерности показали, что тренд имеет грубую точность, но она может быть применена для ориентировочных расчетов, а также для составления прикидочных рекомендаций производству.

А модель с волновыми составляющими с наименьшей погрешностью показывает динамику загрязнения речной воды. Наибольший коэффициент корреляции равен 0.8914 у модели с четырьмя составляющими, из которых три - волновые, что больше в 2.6 раза коэффициента корреляции по тренду. Поэтому сложные по конструкции модели будут полезными для формулировки научных выводов.

\section{Список литературы}

1. Гидрохимические показатели состояния окружающей среды. Справочные материалы / под ред. Т.В. Гусевой. - М. : Форум: Инфра-М, 2007. - 190 с.

2. ГН 2.1.5.1315-03. Предельно допустимые концентрации (ПДК) химических веществ в воде водных объектов хозяйственно-питьевого и культурно-бытового водопользования. - М. : Минздрав России, 2003. 
3. Мазуркин П.М. Факторный анализ загрязнения речной воды / П.М. Мазуркин, О.Ю. Евдокимова. - Йошкар-Ола : МарГТУ, 2011. - 56 с.

4. Мазуркин П.М. Математическое моделирование. Идентификация однофакторных статистических закономерностей / П.М. Мазуркин, А.С. Филонов. - Йошкар-Ола : МарГТУ, 2006. - 292 c.

5. Парфенова Г.К. Антропогенные изменения гидрохимических показателей качества вод. Томск : Аграф-пресс, 2010. - 204 с.

6. СанПиН 2.1.5.980-00. Гигиенические требования к охране поверхностных вод. Санитарные правила и нормы. - М. : Федеральный центр госсанэпиднадзора Минздрава России, 2000. -24 с.

\section{Рецензенты}

Винокурова Раиса Ибрагимовна, д-р биол. наук, профессор, заведующая кафедрой химии, Поволжский государственный технологический университет, г. Йошкар-Ола.

Салихов Мухаммет Габдухаевич, д-р техн. наук, профессор, кафедра автомобильных дорог, Поволжский государственный технологический университет, г. Йошкар-Ола. 